\title{
ALGUNAS NOTAS SOBRE EL PAPEL DE LAGOS Y LAGUNAS COSTERAS PENINSULARES COMO SOPORTES PARA LA NAVEGACIÓN EN ÉPOCA ALTOIMPERIAL
}

\author{
SOME NOTES ON THE ROLE OF IBERIAN LAKES AND COASTAL \\ LAGOONS AS SUPPORT FOR EARLY IMPERIAL NAVIGATION
}

\author{
por \\ MANUEL J. PARODI ÁLVAREZ
}

\begin{abstract}
RESUMEN Los lagos de la Hispania romana debieron sostener un papel como agentes de la comunicación muy limitado, debido a las mismas condiciones naturales de la Península Ibérica. Sin embargo, algunos casos, como los estudiados en el presente trabajo, pudieron representar un rol significativo en determinadas áreas puntuales, básicamente lagunas costeras, como vehículos de comunicación y transporte.
\end{abstract}

\begin{abstract}
The lakes in Roman Hispania enjoyed a strongly limited capability as agents for communication, for the very natural limits of their nature in the Iberian Peninsula. However, in some cases, as those considered in these pages, could have developed a relevant rol in several particular areas, basically in the case of coastal lakes, as vehicles of transport and communication.
\end{abstract}

\section{NOTA INTRODUCTORIA}

Los lagos de Hispania debieron sostener un papel como agentes de la comunicación de carácter muy limitado, debido a las mismas condiciones naturales de las zonas endógenas peninsulares. La Península Ibérica no es rica en grandes extensiones interiores de agua que, por su mera existencia, pudieran prestarse a ser empleadas del modo que los ríos hispano-lusos sí podían hacerlo en bastantes casos como vías de comunicación en época antigua. Además del carácter ya de por sí limitado de un lago ${ }^{1}$ hemos de contar con que Iberia, en contra de lo que sucedía en otras zonas de la Romanidad -como en tierras helvéticasno disponía de una red de lagos intercomunicados entre sí por cursos fluviales naturales o por canales fruto

1. Si la superficie lacustre no cuenta con un curso fluvial que le sirva como desagüe, las barcas no podrán abandonarlo sino con grandes dificultades, al tener que remontar la corriente de los hipotéticos cursos de alimentación que vayan a parar al lago en cuestión. 
de la intervención humana (Pemán 1959; Lazarich et al. 1989)². La relativa escasez y dispersión geográfica de los lagos hispanos tuvieron como consecuencia que el papel de éstos no tuviera la importancia que pudieron tener algunas superficies (o redes) lagunares en otros territorios del Imperio. Los lagos, como las vías fluviales, pueden ser importantes como elementos vertebradores del territorio en el que se insertan; sus aguas sirven como vehículo de comunicación, agilizando los intercambios de todo tipo (económicos, culturales...) y la circulación de personas. Su importancia como tales canales de comunicación está directamente relacionada con su carácter "abierto" o "cerrado"; de esta forma, las superficies lacustres cerradas en sí mismas y no vinculadas a vías acuáticas de diversa naturaleza que les sirvieran de salida, habían de alcanzar una menor proyección (en términos económicos) que aquéllas otras -como, por ejemplo, las suizas-que formasen parte de una red de comunicación de alcance mayor mediante las vías acuáticas antes mencionadas, o que formaran un conjunto comunicado con otros lagos. La zona de influencia de éstos últimos debía ser imaginablemente mayor, "abierta" y de tránsito hacia otras tierras, de modo que podían insertarse en la red de "vías" (en un sentido amplio de la palabra) del Estado Romano ${ }^{3}$.

De acuerdo con M. Sala Sanjaume, "ni las condiciones climáticas ni las del relieve son en la mayor parte de España favorables a la formación de grandes lagos" (lo que es extensible a Portugal); la misma autora continúa: “...tanto por la escasez de agua en la mayor parte de la Península como por la falta de grandes depresiones cerradas, las áreas lacustres son poco importantes" (Sala Sanjaume 1989). Factores como las fuertes pendientes, provocadas por la orografía peninsular, la existencia de niveles freáticos profundos en las zonas menos húmedas (profundidad que impide el afloramiento de esas aguas subterráneas), la escasez general de agua, el escaso número de grandes depresiones cerradas, la naturaleza torrencial de las lluvias en buena parte del territorio ibérico ${ }^{4}$ y la erosión regresiva de los ríos (que altera el paisaje lacustre, ayudando al proceso de colmatación de los lagos), todos ellos, impiden la formación de grandes lagos en territorio hispano. Es cierto que en ríos con un caudal insuficiente puede producirse un fenómeno de acumulación de aguas en zonas deprimidas, pero ello no basta para compensar la escasez general de zonas endógenas que sufre la Península Ibérica.

Aún no siendo demasiado importantes en extensión o cantidad, actualmente existen algunas superficies endógenas de naturaleza tectónica o volcánica en suelo peninsular. Cabe mencionar algunas, como la laguna de La Janda, en Cádiz, con 30-40 $\mathrm{Km}^{2}$ de superficie y alrededor de un metro de profundidad media, el lago de Carucedo, en León, con $565 \mathrm{~m}^{2}$ de superficie o el lago de Bañolas, en Gerona, de $117 \mathrm{Km}^{2}$ de superficie (y que es alimentado por aguas subterráneas procedentes de los Pirineos, por lo que cuenta con una naturaleza mixta). Un lago localizado en el cráter de un antiguo volcán apagado (casi un hápax para la Península Ibérica) es el de Fuentillejo, en el Campo de Calatrava (provincia de Ciudad Real). Otro tipo de zonas lacustres se forma (como hemos ya mencionado) merced a la existencia de corrientes fluviales cuyo caudal es insuficiente; esta insuficiencia de caudal es causa de que las aguas se embalsen, acumulándose en zonas

2. O sea, mediante canales artificiales construidos ex profeso por la mano humana para viabilizar la comunicación entre distintas superficies lagunares, como dice Estrabón que sucedía en el caso de los esteros del Baetis (III, 2, 4-5. 142-144.) o del actual Sado (III, 3, 1. 152.), o como sin duda sucedería en los esteros de la Bahía de Cádiz. Sobre otros canales realizados (o desarrollados como proyecto) para facilitar la navegación lacustre, vid. el caso del lago Sophon, en Asia Menor, y el proyecto de comunicarlo con el mar de Mármara, en Plinio el Joven, Epistulae X, 41-42, 61-62.

3. Una representación de la zona de los lagos suizos, en T. Cornell y J. Matthews (1989). Los lagos "cerrados" contemplarían el desarrollo de los núcleos de población costeros y la relación entre las comarcas circundantes y sus propias aguas, pero serían incapaces de participar en la comunicación de tierras lejanas entre sí por la limitación de sus características físicas. Sobre el papel de los lagos europeos como medios de comunicación en el Estado Romano hablan los hallazgos arqueológicos en ellos realizados; vid. B. Arnold (1975 y 1978); igualmente para los lagos suizos cfr. C. Jullian (1926) y M. Frezouls-Fasciato (1962). Para ejemplos en los marcos balcánico y francés, vid. D.C. Samsaris (1979) y J. Arnal y H. Prades (1980).

4. Lluvias torrenciales cuyos efectos, unidos a la orografía irregular y a la naturaleza del terreno, coadyuvan a la progresiva colmatación y desaparición de las áreas lagunares. 
deprimidas. Se trata siempre de lagunas de escasa magnitud y que sufren un proceso de desecación en la temporada seca que las puede llevar a convertirse en charcas de carácter estacional, desapareciendo en la época estival. Las superficies lagunares de este tipo son habituales en zonas de la Meseta Superior (caso de La Nava de Palencia), en La Mancha y en la depresión del Ebro.

Un tipo distinto de lagunas a tomar en consideración es el formado por agentes exógenos, como los glaciares de montaña. Los ejemplares de este tipo se encuentran en zonas montañosas: los Pirineos (donde existen alrededor de 400 lagos de esta naturaleza), la Cordillera Ibérica, la Cordillera Central (sobre una docena), la Cordillera Bética (unas ocho lagunas de reducido tamaño en Sierra Nevada), y en la Cordillera Cantábrica (donde se sitúa el lago de Sanabria, el mayor de todos los peninsulares, con $318^{\prime} 7 \mathrm{Km}^{2}$ de superficie y 35 metros de profundidad media). Hemos de contar también con los lagos formados por la acción combinada de distintos tipos de suelos (rocas solubles, como yesos y calcáreas) y la existencia de puntos de surgencia de aguas subterráneas. A este grupo pertenecen las lagunas de la cuenca alta del río Guadiana (mencionadas por Plinio, N.H., III, 6.), la de Gallocanta, en la Cordillera Ibérica (con $18 \mathrm{Km}^{2}$ de superficie y $115 \mathrm{~m}$ de profundidad) o la laguna de Fuente de Piedra en la provincia de Málaga, que cuenta con $14 \mathrm{Km}^{2}$ de superficie (Arenillas y Sáenz 1987; Bielza de Ory 1989).

Por último otro tipo de superficies lagunares (y que merece una consideración aparte), es el compuesto por las lagunas litorales, conformadas por la acción combinada del mar, el viento e incluso (en determinados casos) la sedimentación fluvial. Estas lagunas costeras ocupan un puesto de mayor relevancia en la economía de la Hispania Antigua (abundando las menciones de las mismas en las fuentes clásicas), merced a su papel de comunicadores entre las zonas costeras y las comarcas del interior a las que relacionaban físicamente. Entre las lagunas costeras de consideración en Iberia podemos citar las que aún se conservan en la costa levantina (la Albufera de Valencia, el Mar Menor murciano), y algunas existentes en la Antigüedad y ya desaparecidas como tales superficies acuáticas, como la que se extendía por la superficie del actual llano del Almarjal (al N. de Cartagena), o la "Albufereta" (al norte de Alicante, hoy igualmente seca) y las que se forman en la desembocadura de algunos ríos importantes, como el Guadalquivir, el Tajo, el Sado o el Ebro, acerca de las cuales tampoco son escasas las referencias en las obras de los autores antiguos que hacen a la Península Ibérica objeto de su estudio.

\section{EL PAPEL DE LAS SUPERFICIES LACUSTRES IBÉRICAS EN LA ANTIGÜEDAD.}

Descartando el análisis de las lagunas, marismas y esteros formados tanto a lo largo de los cursos fluviales de mayor envergadura como en sus desembocaduras ${ }^{5}$, centraremos nuestra atención en aquellas superficies lacustres que puedan haber gozado de importancia como vías de comunicación en época romana. Se trata básicamente de lagunas costeras, dado que, como hemos adelantado, las zonas endógenas peninsulares son a un tiempo escasas en número, disconexas y lejanas entre sí, y escasamente relevantes por lo que respecta a su calidad como mecanismos de comunicación y transporte.

Por lo que respecta al capítulo de fuentes clásicas, Suetonio cita la existencia de un lago en el país de los cántabros al hablar de los augurios sobre el destino imperial de Galba ${ }^{6}$, sin mencionar el nombre del dicho lago. Acerca de las lagunas que salpican el curso alto del río Guadiana habla Plinio el Viejo, al referir la capacidad del Anas para buscar escondrijos y surgir luego de ellos ${ }^{7}$. Tres lagunas de su tierra de origen son mencionadas por el hispano Marcial en uno de sus textos, sin que se pueda, empero, identificarlas con claridad-como en otros casos (Schulten 1953); finalmente, Apiano, en su descripción del alto Duero, habla

5. Cuya importancia excede los límites de las presentes notas.

6. Suetonio, Galba, VIII.

7. Plinio, Naturalis Historia, III.6. 
(sin demasiados detalles) de ciertas lagunas en las proximidades de Numancia ${ }^{8}$. El papel de estas superficies lacustres en la economía romana (incluso en la peninsular, excepto-si acaso-a niveles puramente locales, de cara al servicio de las comunidades nativas que pudieran aprovechar dichas superficies lacustres como fuente directa de alimento -caza y pesca- más que como vehículos de comunicación) no sólo es difícil de precisar, sino que, a simple vista, parece irrelevante. Sí resulta más interesante, en cambio, el comentario de Apiano ${ }^{9}$ sobre el papel del Durius (y su navegabilidad) de cara al abastecimiento de Numancia; quizá las lagunas del curso alto del Duero pudieran desempeñar también un determinado rol en la economía local y comarcal, como vías de comunicación (quizá este papel se debiera -de forma puntual-al sitio establecido por Roma sobre la ciudad de los numantinos), pero su aparente estacionalidad y dependencia con respecto al río nos hace dudar de que estas lagunas tuvieran realmente un papel mayor que el de proporcionar directamente alimento a los pobladores nativos de la región en forma de la pesca y la caza (Chic 1997) ${ }^{10}$.

Distinta será la situación para las lagunas costeras, acerca de las cuales la información será mayor que la conservada para los lagos interiores. Trataremos sobre las lagunas de la costa mediterránea española, especialmente del Levante valenciano y murciano ". Una de estas lagunas levantinas, mencionada por las fuentes (por Avieno en este caso), es la que Schulten identifica con un estanque en la comarca ampuritana, y que recibiría la denominación de "Stagnum Toni", de acuerdo con el Periplo ${ }^{12}$. Otra laguna menor es aquella sobre cuya existencia hipotetiza el mismo autor -también basándose en los versos de Avienio-y que habría estado al norte de Denia; esta hipotética superficie acuática estaría seca en la actualidad (Schulten 1953). Más palpable parece la existencia de otras lagunas costeras de las cuales quedan referencias onomásticas y topográficas, habiendo desaparecido, sin embargo, como tales paludes. Hablamos, entre otras, del actual llano del Almarjal, al norte de Carthago Nova-Cartagena, de la "Albufereta" (cuyo sólo nombre es orientativo de su pasada condición), al norte de Alicante ${ }^{13}$ o de la laguna de Elche (igualmente seca en la actualidad). Sobre el moderno llano del Almarjal ("la marisma de almarjos") cabe mencionar el papel que desempeñara en la toma de Cartago Nova por las tropas de Escipión el año 209 a.C. Según el arcadiense Polibio ${ }^{14}$, unos pescadores (hemos de entender que naturales de la zona, dado su profundo conocimiento de la misma) habrían sugerido a Escipión la idea de atacar la plaza púnica desde el norte, a través de la laguna, idea que aprovecharon los romanos para conquistar la ciudad. Otro autor, en este caso latino, Tito Livio, cita con posterioridad el mismo evento, identificando a los pescadores como naturales de la Tarraconensis ${ }^{15}$. En cualquier caso, habría de tratarse de indígenas de la zona ${ }^{16}$ con un gran conocimiento de la misma; respecto a las

8. Apiano, Iber., 89-90.

9. Apiano, Iber., 91 .

10. La riqueza de la pesca y caza de la Turdetania es encomiada por Estrabón en su Geografía, III.2.6. (144).

11. Albufera, Mar Menor....

12. Avienio, Ora Maritima, 544. No contamos con ninguna referencia (literaria o epigráfica) acerca de la navegabilidad de dicha laguna.

13. "Almarjal": "Terreno poblado de almarjos./Marjal, terreno bajo y pantanoso".//"Almarjo": "Barrilla, cenizas de esta planta./ Cualquiera de las plantas que dan barrilla"// "Barrilla": "Planta de los terrenos salitrosos de la región Mediterránea y Asia central, de cuyas cenizas se obtenía el carbonato sódico (Familia quenopodiáceas)./Cenizas de esta planta" (Nuevo Diccionario Enciclopédico Larousse (t. 1, “A-Ben”). Barcelona 1994. Sobre el papel de la Albufereta como vía navegable en conexión con el mar cabe destacar la presencia de ánforas Mañá E (púnico-ebusitanas, con una cronología correspondiente al siglo II a.C.) en su ámbito, lo que parece una prueba de su relación con la costa y la navegación marítima y su actividad como punto de recepción de importaciones; vid. Gisbert (1985); vid también Mula y Rosser (1993); igualmente cfr. Abascal (1993) y Llobregat y Rosser (1993); Rubio Gomis (1975).

14. Polibio, X.7.8.

15. Preferimos el término "Tarraconense" al de "Tarragona" empleado por García Bellido (1944), porque entendemos que proporciona un sentido más general (espacial y cronológicamente) que un locativo moderno; la fuente clásica es Livio, A.U.C., XXVI. 45.

16. Si se tratase de pescadores de la región inmediata a Tarraco, no de nativos de la comarca del N. de Carthago Nova, asistiríamos a un fenómeno más complejo, de desplazamientos relativamente lejanos, para dedicarse a faenas de pesca en una laguna no cercana a Tarraco. Pensamos que debía tratarse básicamente (dadas las características de la laguna en cuestión, sometida a la estacionalidad 
formas económicas desarrolladas en la laguna (hoy seca) del Almarjal, debieron orientarse fundamentalmente hacia la actividad primaria (extractiva), puesto que los textos nos citan las labores de pesca como la actividad desempeñada por estos eventuales colaboradores de Escipión (el futuro Africano). Tenemos noticias igualmente sobre la escasa profundidad de la laguna, puesto que los pescadores se veían a veces obligados a recorrerla a pie cuando las barcas tocaban fondo ${ }^{17}$. Debería tratarse, por lo que parece desprenderse de las fuentes, de aguas someras que podrían verse incluso sometidas a un mayor o menor grado de estacionalidad (que reduciría las dimensiones de la superficie de la antigua laguna) y que dependían de la marea (lo que, unido a lo anterior, aumentaría la salinidad de sus aguas).

Otras superficies húmedas conservadas hasta la actualidad (con un tamaño menguado respecto al que tuvieron en la Antigüedad), son la Albufera de Valencia y el Mar Menor de Murcia. Sobre este último habla Estrabón, al describir el paisaje de la comarca de la Nueva Carquedón. Entre los elementos mencionados por el geógrafo anatolio cabe destacar los puertos de Carthago Nova; quizá al mencionar los puertos de la región de Cartagena, nuestro autor esté incluyendo a los fondeaderos naturales de la zona del Mar Menor y el Cabo de Palos ${ }^{18}$. Asimismo, el geógrafo Estrabón menciona la existencia de un lago, cuyas dimensiones en la Antigüedad fija Schulten en 400 estadios (Schulten 1953) ${ }^{19}$. Siempre según Estrabón, en este lago debían existir algunas de las industrias de salazón que proliferaban en la región (como demuestra la factoría de salazones de la Rada del Estacio). Asimismo, esta superficie interior que gozaba de comunicación -al igual que hoy día-con el Mediterráneo debió recibir la parte que le correspondía (por su emplazamiento y condiciones de seguridad de cara al fondeo de las embarcaciones) en el abundante comercio de mercancías llegadas por mar para las gentes del interior, y de productos locales para el mercado exterior, cuyo centro neurálgico se situaba en la metrópolis púnica de la Nueva Cartago ${ }^{20}$.

Otra referencia textual al Mar Menor de Murcia la hallamos en Avienio, quien lo denomina "inmensa palus" ${ }^{21}$ y destaca las dimensiones de lo que, para autores como Estrabón -así como para el propio Festo Avienio-no deja de ser una simple palus, una laguna (pese a su conexión física con el mar Mediterráneo). J. Mas señala -basándose en los restos de material cerámico y los pecios hallados en su seno-hasta media docena de posibles fondeaderos en el Mar Menor, y ello con independencia de los yacimientos submarinos identificables como simples pecios (y no como áreas de apontaje y fondeo para el descanso de las naves, la aguada y el transbordo y desembarque de materiales y pasajeros) que con un arco cronológico que abarca desde el siglo V a.C. hasta época bajoimperial salpican el "polígono submarino del Cabo de Palos" (Mas 1971 y 1985) ${ }^{22}$. No podemos imaginar esta actividad como un fenómeno relacionado exclusivamente con

que provocaba la estación seca, y el conocimiento que de la misma gozaban los colaboradores nativos de Escipión) de habitantes de las proximidades de Carthago Nova, y no de tarragoneses, como parece opinar García Bellido (loc. cit.).

17. Livio, XXVI. 45; de otra parte, esto sucede igualmente hoy día en la Albufera valenciana.

18. Estrabón, Geografía, III.4.6.

19. 400 estadios equivalen a $75 \mathrm{Km}$.

20. Estrabón, III.4.6. (158-9).

21. Avienio, Ora Maritima, 455.

22. Se trata de los fondeaderos de El Mojón, San Pedro del Pinatar, Mar Menor, Isla Grosa y Rada del Estacio, que abarca hasta el Bajo Imperio y cuenta con instalaciones de salazón, haciendo honor al comentario de Estrabón sobre la abundancia de las mismas en la costa levantina (III.4.6; 158). En cuanto a los yacimientos submarinos y su cronología contamos con materiales fenicios procedentes del pecio de La Campana (I) (s. V a.C.) y romanos republicanos (siglos III-I a.C.) de Los Esculls del Mojón (Dr. 1A), el Pecio de la Torre Derribada (S. Pedro del Pinatar, con ánforas grecoitálicas de transición), las Dunas del Pinatar, San Ferreol (Campaniense B, Dr 1B, Lamboglia 2), Punta de Algas (Lamboglia 2 y Campaniense B y C), Pudrimel Sur (Dr. 1C, Campaniense A y cerámica de paredes finas), Las Amoladeras y Bajo de Dentro. Entre los yacimientos de época altoimperial señalados por Mas (siglos I-II d.C.), el Pecio Castillo (formas Beltrán IIA), el Bajo de la Barra y el Pecio Los Espines (Beltrán I), Pudrimel Norte (Dr. 14) y el Bajo de La Campana (II) (con formas IV de Beltrán); de cronología bajoimperial (siglos III-V d.C.) son los yacimientos de Escolletes I y II, relacionados con el fondeadero de El Estacio (con ánforas Almagro 51C) y la isla de la Hormiga (con ánforas cilíndricas africanas). Para la difusión en época prerromana por el interior de las importaciones orientales canalizadas 
el Mar Menor, sino que debemos entenderla como una fase en la navegación de cabotaje por las costas españolas en las rutas comerciales hispanas con el Mediterráneo Central y Oriental; más en concreto, hemos de relacionar la gran laguna costera murciana con las relaciones y contactos entre el interior de su región y el exterior peninsular: como foco de recepción (y de salida) de objetos de comercio, como plantea Estrabón.

Estas lagunas costeras están directamente relacionadas con la navegación marítima, a la que servían como descansaderos, puntos de aguada y fondeaderos (funcionando en este sentido de manera homóloga a la desembocadura de ríos y ramblas costeras -e incluso de simples ensenadas-que proporcionaban fondeaderos y embarcaderos relativamente cómodos y seguros para las naves de la época). Lagunas como las de la Albufera, las de la Almenara (al sur de la provincia de Castellón) o el Mar Menor (en mayor medida en el caso de este último, a juzgar por los restos materiales que como veíamos proporciona) presentan evidencias notables de su navegación como fondeaderos, pecios (en el caso del Mar Menor, por ejemplo) e incluso restos arquitectónicos de diversa naturaleza, estando en relación con puntos importantes de la costa (entre los que se cuentan enclaves urbanos de relieve, como Valentia-Valencia-ciudad que cuenta para su servicio con las aguas y desembocadura del río Turia, así como con el fondeadero costero de la cercana playa de El Saler), incluso en el caso de no encontrarse inmediatamente junto a éstos. A. Fernández pone de manifiesto la relación entre los pecios y hallazgos submarinos de las costas valencianas y los fondeaderos proporcionados por las desembocaduras de los ríos de la región y las lagunas costeras de la misma, como las que se extendían por la comarca de Torrelasal (Ribera de Cabanes, Castellón) ${ }^{23}$.

En el caso de las lagunas de la Almenara, situadas igualmente en la provincia de Castellón, G. Martín las identifica con la "Palus Naccararum" mencionada por el texto de Festo Avieno, argumentando que en su recorrido de S. a N., el autor de la Ora Maritima cita dicha "palus" después que a Sagunto ${ }^{24}$. Esta superficie lagunar debió haber estado comunicada de forma directa con el mar, por lo que pudo haber servido como puerto y refugio para las naves marinas (ya que la mayor de las lagunas supervivientes presenta una profundidad entre 14 y 8 metros, lo que permitiría sobradamente la navegación de las naves de cabotaje, sin contar con el proceso de colmatación que dichas "paludes" habrían sufrido) además de como punto de aguada para las mismas. Ya desde fines del siglo XVIII de la Era se han reconocido restos de edificaciones interpretados como pertenecientes a embarcaderos romanos en las aguas de los muy transformados Estanques de la Almenara (Martín Ávila 1971) ${ }^{25}$, y Alcina (1950) no duda en relacionar estas lagunas con la navegación costera y la ciudad de Sagunto en la Antigüedad, a la que pudieran haber servido como fondeadero.

Una más de las lagunas litorales levantinas, a la que mencionábamos antes, es la Albufera de Valencia, “...hoy cada vez más reducida debido a la sedimentación y al cultivo del arroz..." (Schulten 1953). Pese a su comunicación directa con el mar, la superficie de aguas someras de la Albufera sigue-como sucediera con el Mar Menor murciano, de mayores dimensiones que la laguna valenciana-manteniendo su considera-

a través de los fondeaderos y puntos de desembarco del litoral levantino en la región del Mar Menor (laguna que debía, como venimos insistiendo, cumplir una importante función-como demuestran los fondeaderos y yacimientos submarinos de la misma y su frente marítimo-de cara al intercambio cultural y comercial entre el interior de su región y el Mediterráneo oriental y central), vid. J.M. García Cano (1985).

23. Sobre las lagunas de Albalat y la Boca de l'Infern, en la costa de Castellón-Ribera de Cabanes-(zona que tuvimos la fortuna de conocer personalmente durante nuestra participación en las campañas de excavación de la Excma. Diputación Provincial de Castellón en el yacimiento de Torrelasal de los años 1990 y 1993, dirigidas por la Dra. Fernández Izquierdo), vid. Fernández (1980); este embarcadero, relacionado con el poblado ibérico de Torrelasal, núcleo destruido en el siglo I a.C. (con niveles de ceniza que evidencian su destrucción por el fuego, sin un posterior reaprovechamiento, en lo que podríamos ver un efecto de las luchas entre Sertorio y Pompeyo), presenta una cronología entre los siglos III-I a.C (Wagner 1978).

24. Avienio, Ora Marítima, 492.

25. Respecto a las construcciones, se trata de un muro “...que recorre en toda su longitud la ribera E. del estanque...", y de una torre, ambos en el Ullal Mayor (G. Martín 1971), de forma circular (no pensamos que la reducción que de la "torre" hace la autora interpretándola como un horno cerámico pueda ser tenida por concluyente en función de los datos que se manejan). 
ción de lago para los autores clásicos; así, Plinio el Viejo la califica de "amoenum stagnum", amena laguna ${ }^{26}$. Sobre su identificación con la laguna en la que desapareciera la cierva sagrada del rebelde Sertorio tras la batalla entre éste y Pompeyo ( 75 a.C.) no podemos sino remitirnos a Schulten (1953), quien la establece de ese modo ${ }^{27}$. Esta amena laguna debió canalizar las relaciones comerciales de su región, dadas las condiciones generales de inseguridad de la costa levantina en la Antigüedad y la relativa escasez de abrigos naturales seguros en ésta (García Bellido 1944), excepción hecha de las bocas de ríos y las lagunas costeras; con todo, la escasa profundidad de sus aguas pudo constituir una limitación para sus potencialidades como vía de comunicación entre el interior y la costa, pero sólo en lo que se refiere a la evolución de naves de cabotaje marítimas, ya que sus aguas serían suficientes para el desenvolvimiento de las auxiliares de dichas naves marinas, las cuales servirían para conectar a las primeras con la tierra firme, así como para el embarque y desembarque de mercancías y pasajeros.

En este sentido, las actividades extractivas (junto a las de comunicación antes apuntadas) desarrolladas desde embarcaciones de reducido desplazamiento y escaso calado debieron suponer uno de los principales esfuerzos económicos desarrollados por los nativos de la zona, como parecen demostrar las propias condiciones naturales del medio en cuestión (a destacar su riqueza piscícola y faunífera); no puede desdeñarse tampoco la importancia de las actividades comerciales: varios autores han puesto de manifiesto la relación entre los restos y yacimientos submarinos de la costa de la ciudad de Valencia y los fondeaderos costeros que tanto el río Turia como la propia Albufera ofrecen de manera natural a la ciudad de Valentia (Fernández 1984; Gisbert 1985; Ribera y Fernández 1985). De hecho, los restos que aparecen en el fondeadero identificado por A. Fernández en la valenciana playa del Saler tienen su arranque cronológico en el momento en que sabemos que se produce la fundación de la Valencia romana, esto es, la segunda mitad del s. II a.C. (Fernández 1984). Es esta misma investigadora quien hace un mayor hincapié en el papel de la Albufera en la conexión de la Valencia romana con el mar y el fondeadero del Saler: según esta autora, la laguna de la Albufera, por sus mayores dimensiones y profundidad en la Antigüedad, habría resultado una vía segura para aproximarse (por vía acuática interior) a la ciudad mediante las barcas menores a las que personas y cosas debían transbordar desde las naves marinas (en puntos como el fondeadero del Saler), evitándose de este modo los peligros del transbordo en plena mar; ello explicaría el emplazamiento de este fondeadero relativamente lejos de la propia ciudad, ya que su relación con la misma no se establecería de un modo directo sino a través de la intermediación de la Albufera (con la que sí tiene el Saler una relación directa de proximidad) ${ }^{28}$.

Una conocida representación del desarrollo de las actividades humanas en el marco de estas lagunas litorales levantinas es la mostrada por los vasos de Liria (García Bellido 1944) ${ }^{29}$. Se trata de una serie de

\section{Plinio, Naturalis Historia, III.20.}

27. Aulo Gelio, XV.22.6.

28. Los materiales anfóricos de cronología más antigua recuperados pertenecen a las tradiciones púnica (Mañá $E$ ) y grecoitálica; a éstos se suman Dr. 1A-B, Lamboglia 2 y producciones de transición o plenamente imperiales (Dr. 2/4, Dr. 7/11, Dr. 20, Dr. 28, Dr. 30/Pelichet 47/Gauloise 4, Beltrán II-B, Pelichet 46), hasta llegar a producciones tardías que evidencian el uso del fondeadero del Saler hasta época bajoimperial (con restos de tipos Almagro 50, Africanas Grande y Pequeña); vid. A. Ribera y A. Fernández, 1985; sobre la fecha de la fundación de Valentia, vid. J.-N. Bonneville, R. Etienne, P. Rouillard, P. Sillières, A. Tranoy (1982); igualmente, M.A. Marín (1988).

29. En dos de estos vasos hallados en la localidad levantina de Liria, en la provincia de Valencia, se narra una escena de persecución en un ambiente que según García Bellido se localiza en "...cualquiera de las charcas litorales de las cercanías de Valencia". Una embarcación tripulada por varios individuos armados con arcos y flechas persigue a otra más pequeña pilotada por solo dos tripulantes, mientras desde tierra, junto a unas chozas construidas sobre pilotes, otro individuo parece disparar sus flechas contra la embarcación perseguidora, en defensa de la que huye, siendo su ataque contestado desde la barca mayor. Ambas embarcaciones presentan en sus proas sendas cabezas de animales, y la mayor de las dos parece aprovechar también la fuerza del viento para desplazarse, ya que muestra una rudimentaria vela sostenida entre dos mástiles. Se trata en este caso de embarcaciones de escaso calado y bien preparadas para la navegación en aguas someras (en el caso de una de ellas podría tratarse 
vasos ibéricos hallados en Liria (Valencia), en la decoración pictórica de uno de los cuales se desarrolla una escena cuyo marco natural debe haber sido "...cualquiera de las charcas litorales de las cercanías de Valencia" (García Bellido 1944). Al margen del tema central desplegado en la narración visual ${ }^{30}$, fijaremos nuestra atención en los elementos "secundarios" de la escena; aparecen varios ejemplos de lo que parecen ser casas palafíticas, propias de un ambiente lacustre, la representación de un équido, lo que no entra en absoluto en contradicción con un escenario de marisma ${ }^{31}$, y barcas de escaso bordo, aptas para la navegación en unas superficies lagunares que -como era el caso del llano del Almarjal, al norte de Cartagena-podrían incluso secarse parcialmente en los períodos de mayor sequedad ambiental, sufriendo la reducción de su superficie.

Además de los elementos citados es digna de mención la representación estilizada de un ave y de hasta diez peces. Es notable la cantidad de peces dibujados (se trata del elemento más repetido, por encima del tipo humano, que aparece en seis ocasiones: cinco en las barcas y otro en tierra; o del equino y el aviforme -con un ejemplar en cada caso), así como las diferencias de tamaño entre ellos. Con toda certeza se está destacando la principal actividad económica desarrollada por los nativos en la zona ${ }^{32}$ mediante la representación de lo más característico de la misma; nos referimos a la pesca, simbolizada en el abundante número de peces que se dan cita a todo lo largo de la escena (excepto en la esquina donde el individuo, presuntamente desde tierra firme, lanza sus flechas contra la mayor de las dos embarcaciones).

Buena parte de los ejemplos contemplados han de ser fechados en época prerromana, como la navegación que muestran los vasos de Liria o la ayuda brindada por los pescadores de la -entonces- laguna sita en el murciano llano del Almarjal a las tropas de Escipión para conquistar la Nueva Carquedón (209 a.C.); pese a ello podemos pensar que la situación no variaría esencialmente en época romana. La naturaleza de las lagunas haría de ellas buenos refugios -en el caso de las que estuvieran conectadas con el mar-pero sus condiciones de estacionalidad, escasa profundidad y progresiva colmatación, harían inviable su navegación -especialmente en las lagunas "cerradas"- de otros medios que no fueran los sutiles; su papel económico debió así pues ceñirse en buena medida a las actividades extractivas descritas ${ }^{33}$.

incluso de una barca monóxila), en un ambiente prerromano, pero resultan harto ilustrativas del uso bélico de las naves en los cauces interiores y zonas lacustres.

30. El motivo bélico del enfrentamiento entre las tripulaciones de dos barcas.

31. La borda de ambas naves es tan baja que se aprecian las rodillas flexionadas de alguno de sus tripulantes; el autor habría representado la naturaleza real de las barcas y sus proporciones, las más convenientes para una navegación por aguas poco profundas. Otra característica de las barcas lacustres hispanas -como muestran testimonios de otras regiones del Imperio- sería contar con fondo plano (como refleja Plinio en el caso de las barcas de los pescadores de la Tarraconense relacionados con el sitio de Carthago Nova por Escipión), lo cual resultaría muy ventajoso para navegar por aguas tranquilas y poco profundas como lagos, lagunas y marismas. Se trata de lo que D. Hakelberg (1990) denomina "bottom-based construction", aspecto técnico éste (el fondo plano) que M. Eckoldt hace imprescindible para la navegación por vías menores (aquéllas cuya corriente media está por debajo de los 20m3/s. (Eckoldt, 1984); es un tipo de barcas de uso extendido en el Imperio, de cuya presencia tenemos constancia material en Francia, Suiza y Países Bajos (Arnold 1990 y 1992; de Weerd 1978); las naves mostradas podrían ser monóxilas (especialmente la más pequeña), como las estudiadas por S.V.E. Heal y G.Hutchinson (1986), quienes no proponen una cronología concreta para ninguna de las tres embarcaciones (sólo una estimación aproximada para la primera de las que analizan, la que fue hallada en Chamberlains Wharf, Southwark: de acuerdo con los niveles de sedimentación y los materiales del relleno del canal donde fue hallada, los autores la sitúan cronológicamente entre tiempos romanos y medievales). Otro tipo de embarcaciones de naturaleza distinta es el representado por los dos barcos de recreo romanos de época imperial encontradas en el lago Nemi, cerca de Roma, las cuales databan del s. I d.C. y medían $73 \times 24$ y $71 \times 20$ m. respectivamente (Greene 1986; Ucelli 1950), cuyas características y naturaleza (se trata de dos grandes embarcaciones de recreo) responden a las potencialidades del Estado Romano.

32. Si bien un combate puede ser el habitual motivo "heroico" a inmortalizar, el marco en el que se inserta no deja lugar a dudas: una de las principales actividades económicas desarrolladas en la laguna debía ser la extractiva, la pesca (y la caza de ánades y demás aves).

33. Como la caza, cuya importancia comenta Estrabón III.2.6. (144) para el caso de la Turdetania, e, insistimos, las actividades cinegéticas (caza y pesca), como los vasos de Liria y las fuentes (Polibio y Livio, entre otros) indican. 


\section{BIBLIOGRAFÍA}

ABASCAL, J.M. (1993): "Hallazgos epigráficos y numismáticos en las excavaciones del área del Tossal de Manises (1987-1990)", LQNT 1: 137-152.

ALCINA FRANCH, J. (1950): “Las ruinas romanas de Almenara (Castellón). Informe preliminar”, Boletín de la Sociedad Castellonense de Cultura VII.

ARENILLAS PARRA, M. y SÁENZ RIDRUEJO, C. (1987): Guia Física de España, III. Los Ríos. Madrid ARNAL, J. Y PRADES, H. (1980): “Les ports lagunaires de la region de Montpellier", BuMAM.: 24.

ARNOLD, B. (1975): "The Gallo-Roman boat from the Bay of Bevaix, Lake Neuchâtel, Switzerland", IJNA, 4.1 .

(1978):“Gallo-Roman boat finds in Switzerland", en J. du Plat Taylor y H. Cleere (Eds.) Roman Shipping and trade: Britain and the Rhine province. Londres.

(1990): "The heritage of log boats and Gallo-Roman boats of lake Neuchâtel: technology and typology", en S. McGrail (Ed.), Maritime Celts, Frisians \& Saxons, CBA Research Report, 71.

BONNEVILLE, J.-N.; ETIENNE, R.; ROUILLARD, P.; SILLIÈRES, P.; TRANOY, A. (1982): "Les villes romaines de la Péninsule Ibérique", en Les villes dans le Monde Ibérique: 11-23. París.

CORNELL, T. Y MATTHEWS, J. (1989): Roma, legado de un Imperio. Barcelona.

CHIC GARCÍA, G. (1997): Historia Económica de la Bética en la época de Augusto. Sevilla.

ECKOLDT, M. (1984): "Navigation on small rivers in Central Europe in Roman and Medieval times", IJNA, 13.1: 3-10.

FERNÁNDEZ IZQUIERDO, A. (1980): "Estudio de los restos arqueológicos submarinos en las costas de Castellón", CPAC 7: 158-165.

(1984): Las ánforas romanas de Valencia y de su entorno marítimo. Valencia.

FREZOULS-FASCIATO, M. (1962): "Notes sur Verone, Brescia et la battéllerie du lac de Garde aux trois premiers siècles de notre ère", en Hommages à Albert Grenier, II. Coll. Latomus, LVIII. Bruselas.

GARCÍA BELLIDO, A. (1944): "La Navegación Ibérica en la Antigüedad según los textos clásicos y la Arqueología", en Estudios Geográficos, 16: 511-560.

GARCÍA CANO, J.M. (1985): "Cerámicas áticas de figuras en el sureste peninsular", en Ceràmiques gregues $i$ helenístiques a la Península Ibèrica: 59-64. Barcelona.

GISBERT, J.A. (1985): "Hallazgos arqueológicos submarinos en la costa de Denia. Las ánforas de cronología romana republicana", VI CIAS: 411-424. Madrid.

GREENE, K. (1986): The Archaeology of Roman Economy. London.

HAKELBERG, D. (1990): “A 14th.-century vessel from Immenstaad (Lake Constance, southern Germany)”, IJNA 25: 3-4.

HEAL, S.V.E. y HUTCHINSON, H. (1986): "Three recently found logboats”, IJNA 15.3: 205-213.

JULLIAN, C. (1926): “Les nautes du Leman", REA 28.

LAZARICH, M. et alii, (1989): "Prospección arqueológica superficial de la campiña sur gaditana: término de Puerto Real", $A A A$, II.

LLOBREGAT, M. y ROSSER, P. (1993): “Un fragmento cerámico con grafitos bilingües y la pervivencia del sustrato ibérico en la ciudad romana del Tossal de Manises (Albufereta, Alicante)", LQNT 1: 119-136.

MARÍN, M.A. (1988): Emigración, Colonización y Municipalización en la Hispania Republicana. Granada.

MARTÍN ÁVILA, G. (1971): "El problema de las lagunas de la Almenara", III CIAS, ISL-Bordighera: 91-99. 
MAS, J. (1971): "La nave romana de Punta de Algas", NAH XIII-XIV, Madrid.

(1985): "El polígono submarino del Cabo de Palos. Sus aportaciones al estudio del tráfico marítimo antiguo", VI CIAS: 153-171. Madrid

(1985): "Excavaciones en el yacimiento submarino de San Ferreol (Costa de Cartagena)", VI CIAS: 189-224. Madrid.

MULA, J. Y ROSSER, P. (1993): "El poblado ibérico amurallado del "Cerro de las Balsas" (Albufereta, Alicante): resultados preliminares de los sondeos practicados por el Cophiam (1990-1991)", LQNT 1: 105-118.

PEMÁN PEMARTÍN, C. (1959): “Alfares y embarcaderos de la provincia de Cádiz”, AEArq. XXXII.

RIBERA, A. y FERNÁNDEZ, A. (1985): "Prospecciones arqueológicas submarinas en la zona del Saler (Valencia)", VI CIAS: 83-92.

RUBIO GOMIS, F. (1975): "La cerámica de importación de la necrópolis de la Albufereta (Alicante)", CUPAUAM 2: 105-106.

SALA SANJAUME, M. (1989): "Las aguas continentales", en V. Bielza de Ory (Coord.), Territorio y Sociedad en España, I. Geografía Física: 257-296. Madrid

SAMSARIS, D.C. (1979): "La navigation dans l'ancien lac du Cercinitis d'après une inscription inedite trouvèe dans le village actuel de Paralimnion de Serrès", Makedonika 19.

SCHULTEN, A. (1953): Geografía y Etnografía Antiguas de la Península Ibérica (II). Madrid.

SIMMONS, B.B. (1979): “The Lincolnshire Car Dyke: navigation or drainage?”, Britannia, 10: 183-196.

UCELLI, G. (1950): Le navi di Nemi. Roma.

WAGNER, G. (1978): "El yacimiento submarino de Torre de Sal, Cabanes (Castellón)", CPAC 5.

DE WEERD, M.D. (1978): "Ships of the Roman period atZwammerdam/Nigrum Pullum, Germania Inferior", en J.du Plat Taylor y H. Cleere, Roman Shipping and Trade: Britain and the Rhine provinces. Londres: $15-22$. 